\title{
Biological and Molecular Characterization of a New Cucurbit-Infecting Tobamovirus
}

\author{
Y. Antignus, Y. Wang, M. Pearlsman, O. Lachman, N. Lavi, and A. Gal-On
}

Department of Virology, ARO, The Volcani Center, P.O. Box 6, Bet Dagan, 50250, Israel.

Accepted for publication 21 February 2001.

\begin{abstract}
Antignus, Y., Wang, Y., Pearlsman, M., Lachman, O., Lavi, N., and Gal-On, A. 2001. Biological and molecular characterization of a new cucurbit-infecting Tobamovirus. Phytopathology 91:565-571.

An uncharacterized virus was isolated from greenhouse-grown cucumber plants. Biological and serological data described in the present study indicated that the virus belonged in the genus Tobamovirus. The host range of the virus included several plant species within the family Cucurbitaceae. The virus designated Cucumber fruit mottle mosaic virus (CFMMV) causes severe mottling or mosaic on cucumber

Tobamovirus. However, its sequence was distinct from other described viruses within the group of cucurbit-infecting Tobamoviruses. Comparisons of sequences and phylogenetic analysis suggested that the cucurbit-infecting Tobamoviruses be separated into two subgroups: subgroup I comprising the strains and isolates referred to in the literature as Cucumber green mottle mosaic virus (CGMMV) (CV3, CV4, CGMMVW, CGMMV-SH, and CGMMV-Is) and subgroup II comprising CFMMV, Kyuri green mottle mosaic virus (KGMMV), and the Yodo strain of CGMMV, which is closely related to KGMMV and may be considered a strain of it.
\end{abstract} fruits, and its fast spread within greenhouses could lead to significant economic losses in cucumber crops. The genome of CFMMV has been completely sequenced and its genome organization was typical of a
Additional keywords: dot spot hybridization, genome organization, western blots.
Cucumber green mottle mosaic virus (CGMMV) is a member of the genus Tobamovirus causing a severe disease of cucurbits. Strains of CGMMV were first reported from the United Kingdom and Europe (1). The type strain, Cucumber virus 3 (CV3), does not cause fruit symptoms in cucumber, but produces a few local lesions in Chenopodium amaranticolor under specific conditions, and does not infect Datura stramonium or Petunia hybrida (1). Cucumber virus 4 (CV4) was originally described by Bewley and referred to as CV4 by Ainworth (1); it can induce conspicuous fruit symptoms in cucumber, and produces local lesions in Chenopodium amaranticolor but not in $D$. stramonium. CV3 and CV4 are very similar, both chemically and serologically (22). In Japan, three different strains have been described: the "cucumber strain" (CGMMV-C) causes severe fruit distortion in cucumber and induces local lesions in D. stramonium but not in Chenopodium amaranticolor (17); the "Yodo strain" (CGMMV-Y) causes local lesions in both Chenopodium amaranticolor and D. stramonium (18); and the "Watermelon strain" (CGMMV-W) causes severe disease symptoms in infected watermelon plants and induces local lesions in Chenopodium amaranticolor but not in D. stramonium (19). Another Tobamovirus, isolated in Japan from greenhouse muskmelons, exhibiting leaf mosaic and necrotic lesions on the fruit was designated CGMMV-SH. The full genome of this strain was sequenced and found to be highly similar, both serologically and in sequence to CGMMV-W $(28,30)$.

An additional strain (Indian strain C) was isolated in India from bottle gourd and induces local lesions in Chenopodium amaranticolor, but no symptoms on D. stramonium (33).

Corresponding author: Y. Antignus; E-mail address: antignus@ias.agri.gov.il

Y. Wang and Y. Antignus contributed equally to this work.

Publication no. P-2001-0328-01R

This article is in the public domain and not copyrightable. It may be freely reprinted with customary crediting of the source. The American Phytopathological Society, 2001.
Hybridization analysis has shown that CV4 isolates do not have any detectable similarity with RNA from the Japanese CGMMVC (31), but this analysis revealed a high degree of similarity between strains CV3 and CV4 (23). Francki et al. (9) pointed out that CV3, CV4, and CGMMV-W are serologically closely related and have a high degree of RNA sequence similarity. Based on these results, they proposed that these isolates are strains of the same virus. Moreover, the lack of detectable sequence similarity and the remote serological relationship between these isolates and CGMMV-C led them to consider that the latter is a distinct virus, which they named Kyuri green mottle mosaic virus (KGMMV). Recent studies indicate a close relationship between the Yodo strain of CGMMV and KGMMV, thus designated KGMMV-Y (28).

Our study was designed to characterize a cucurbit-infecting Tobamovirus isolated from greenhouse cucumbers in Israel. It presents, to the best of our knowledge, the first information on the biological, serological, genome organization, and complete nucleotide sequence of this new virus designated as Cucumber fruit mottling mosaic virus (CFMMV). Amino acid and nucleotide sequence alignments of the coding and noncoding genome regions, as well as a phylogenetic analysis of CFMMV and various cucurbit-infecting Tobamoviruses, are used to clarify the taxonomic status of this virus and also of other viruses within this group.

\section{MATERIALS AND METHODS}

Virus source and maintenance. The new Tobamovirus under study was isolated from infected commercially grown cucumbers in greenhouses. For purpose of discussion, it was designated CFMMV. CFMMV and the Israeli variant of CGMMV (CGMMV-Is) (2) were maintained on cucumbers (Cucumis sativus). Pepper mild mottle virus (PMMV pathovars 1,2, and 3) and Tomato mosaic virus (ToMV) were maintained on pepper and tomato plants, respectively. Cultures of the viruses were renewed 
by mechanical inoculation. All plants were kept in an insect-proof greenhouse that was treated regularly with insecticides.

Purification. Tobamoviruses were purified essentially as described by Tung and Knight (29). An extinction coefficient of $E_{260 \mathrm{~nm}}{ }^{0.1 \%}=3.18$ (34) was used to estimate virus concentration spectrophotometrically. The quality of virus preparations was examined by electron microscopy.

Antisera. Antiserum against strain CV4 of CGMMV was provided by B. von Vechmar, University of Cape Town, Rondebosch, South Africa. Antisera against CGMMV-Is, ToMV, PMMV, and CFMMV were produced as described by Antignus et al. (2). Commercial antiserum kits against CGMMV were purchased from R. F. A. Sauerlach (Loewe Biochemica GmbH, Germany) and from Agdia Inc. (Elkhart, IN).

Polyacrylamide gel electrophoresis and western blots. Purified virus preparations were separated on $10 \%$ gels containing $0.4 \%$ sodium dodecyl sulfate (SDS) according to Laemmli (20). Protein bands were visualized by staining with Coomassie brilliant blue. For western blot analysis, proteins were blotted onto nitrocellulose membranes with a Mini Trans Blot Device (BioRad Laboratories, Richmond, CA).

Immunostaining was carried out as described by Hibi and Saito (14), with the homologous antiserum used as first antibody at 1:500 dilution, except in the case of CFMMV, in which a 1:5,000 dilution was used.

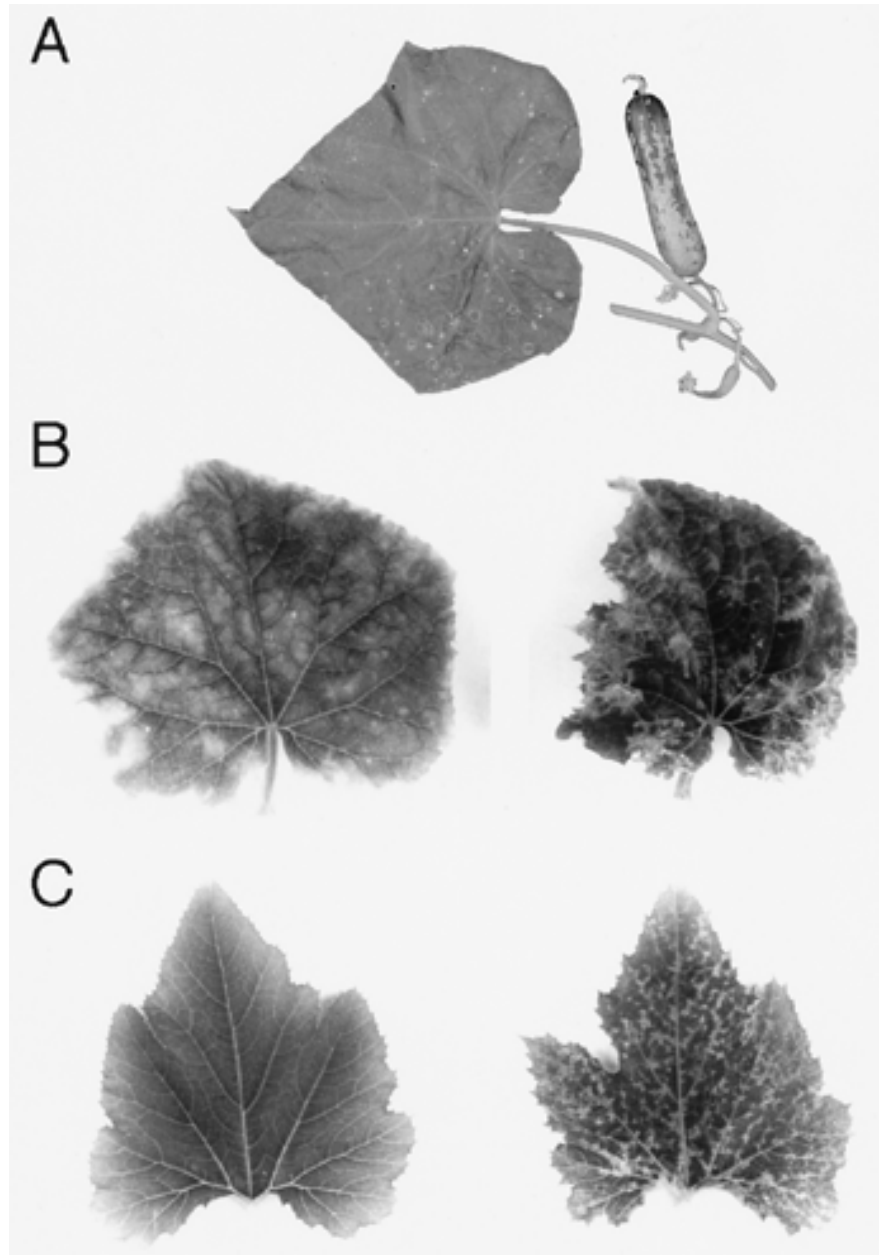

Fig. 1. Symptoms of Cucumber fruit mottle mosaic virus (CFMMV) in cultivated cucurbits. A, Fruit symptoms induced by natural infection in cucumber (Cucumis sativus cv. Hassan). B, Leaf symptoms in mechanically inoculated cucumber (Cucumis sativus cv. Beit alfa) with CGMMV-Is (left) and CFMMV (right). C, Leaf symptoms in mechanically inoculated zucchini squash (Cucurbita pepo cv. Maayan) with CGMMV-Is (left) and CFMMV (right).
Enzyme-linked immunosorbent assay analysis. Double antibody sandwich, enzyme-linked immunosorbent (DAS-ELISA) tests of purified virus preparations were performed as described by Clark and Adams (5). The commercial antisera and conjugates were used at 1:200 dilution as recommended by the manufacturers. The antisera against CGMMV-Is and against CFMMV were used for coating at 1:500 dilution, whereas their conjugates were diluted to 1:1,000. All assays included controls consisting of a purified preparation of the unrelated Zucchini yellow mosaic virus to estimate the nonspecific background. Optical densities for samples within plates were recorded at $405 \mathrm{~nm}$ with a plate reader (Anthos Labtec Instruments, Salzburg, Austria).

RNA extraction. Viral RNA was extracted from purified virus preparation by incubation in $0.5 \%$ SDS following phenol chloroform extraction (24).

Total RNA from CFMMV and CGMMV-Is-infected melon plants was extracted approximately 30 days postinoculation. Each sample consisted of three leaf discs (1-cm diameter) from which total RNA was extracted with an RNA extraction kit (Tri Reagent; Molecular Research Center, Cincinnati).

Cloning of the full-length genome of CFMMV. The cDNAs of CFMMV were synthesized by the Universal RiboClone cDNA Synthesis System with Random Hexameric Primers (Promega, Madison, WI) according to manufacturer's protocol. The cDNAs were cloned into the blunt-ended site of pUC57 (Fermentas, Valnius, Lithuania), designated pUC57-EcoRV, and sequenced. Nucleotide sequence alignment with CGMMV (SH strain, GenBank Accession No. D12505) identified three useful fragments: one near the $5^{\prime}$ end $(\approx 400 \mathrm{bp})$ of the genome, one in the middle of the genome $(\approx 2.9 \mathrm{~kb})$, and one at the beginning of the coat protein $(\mathrm{CP})(\approx 5.8 \mathrm{~kb})$, but none of the cDNAs represented the extreme ends of the CFMMV genome.

To determine sequences of the $5^{\prime}$ and $3^{\prime}$ extreme ends of the CFMMV genome, $5^{\prime}$ and $3^{\prime}$ rapid amplification of cDNA ends (RACE) were performed on double-stranded RNAs (dsRNAs) (11). The dsRNAs of CFMMV were extracted from infected squash plants (Cucurbita pepo cv. Maayan) with CF11 cellulose chromatography according to the method described by Dodds (7). The dsRNAs were polyadenylated at $3^{\prime}$ ends using poly (A) polymerase (Amersham, Cleveland) as described by Frohman (11). The $5^{\prime}$ and $3^{\prime}$ RACEs were performed with $C$. therm polymerase for reverse transcription in two-step RT-PCR kit (Boehringer $\mathrm{GmbH}$, Mannheim, Germany) combined with expand long template PCR kit (Boehringer). An oligo (dT) 17 primer and the orientation-specific primers ( $5^{\prime}$ RACE antisense primer $5^{\prime}$ TGC TCT CCC CTT CAG CAT ATG 3', 425-405; and 3' RACE sense primer $5^{\prime}$ TCT TAC TCT ACT TCT GGT 3', 5848-5866) were used for the above reactions. The products of the $5^{\prime}$ and $3^{\prime}$ RACEs were cloned into pUC57-EcoRV to create clones pUC-5' RACE and pUC-3' RACE. Both clones were sequenced and, based on their nucleotide sequence, two primers were designed to amplify the entire viral genome: a sense $5^{\prime}$ end primer (5' GAT AAA AGT TTT TTA CAT TGA AC $3^{\prime}, 1-23$ ) representing the extreme $5^{\prime}$ end of the viral genome, and an antisense $3^{\prime}$ end primer $\left(5^{\prime}\right.$ TGG GCC CCT ACC CGG GG 3', 6571-6555) complementary to the extreme $3^{\prime}$ region of the viral genome. Attempt to amplify the fulllength cDNA of the entire genome with these primers failed probably due to secondary structure at $3^{\prime}$ end of the RNA genome (6). Therefore, two reverse transcription polymerase chain reactions (RT-PCRs) were carried out with an expand RT kit (Boehringer) together with an expand long template PCR system (Boehringer) to clone large cDNAs. An $\approx 3$-kb fragment was amplified using the sense $5^{\prime}$-end primer and an antisense primer complementary to the middle portion of the proposed viral genome (5' CAG ACC GGT ATG CAC CAT GAG AC 3', 29572935). An $\approx 3.3-\mathrm{kb}$ fragment that includes the $3^{\prime}$ part of the genome except the $3^{\prime}$ noncoding region (NCR) and overlapping with the $3^{\prime}$ end of the former fragment was obtained using a sense 
primer from the middle portion of the viral genome (5' CTC ATG GTG CAT ACC GGT CTG 3', 2937-2957) and an antisense primer complementary to the end of CP (5' CTT CGA GGT AGA CGA CGA 3', 6331-6314). Both fragments were cloned into pUC57-EcoRV to produce clones pUC-5' $3 \mathrm{~kb}$ and pUC-3' $3.3 \mathrm{~kb}$. The full-length sequence of CFMMV genome was derived by sequencing pUC-5' $3 \mathrm{~kb}$ and pUC-3' $3.3 \mathrm{~kb}$ and pUC-3' RACE containing the $\mathrm{CP}$ gene and the $3^{\prime}$ NCR of CFMMV.

Cloning of the CP gene of CGMMV-Is. The CP gene of CGMMV-Is was cloned by RT-PCR (16). First strand cDNA was synthesized with a primer complementary to the $3^{\prime}$ of the gene $\left(5^{\prime}\right.$ CTTTCGAGTGGTAGCCTCTGA-3'). This primer and a sense primer (5'-GCTTACAATCCGATCACACCT-3') were used to amplify the cDNA product of the first strand synthesis. The primer sequences were taken from sequence data of CGMMV-W (identical to CGMMV-SH) deposited in GenBank (Accession No. V01551). PCR conditions were as follows: 35 cycles of $30 \mathrm{~s}$ at $94^{\circ} \mathrm{C}, 30 \mathrm{~s}$ at $55^{\circ} \mathrm{C}$, and $30 \mathrm{~s}$ at $72^{\circ} \mathrm{C}$. The resulting RT-PCR fragment was cloned into pGEM T-vector (Promega).

Dot spot hybridization. Equal amounts of virion RNAs or total RNAs from CGMMV-Is and CFMMV-infected cucumber plants were spotted onto nylon membranes Hybond-NX (Amersham, Buckinghamshire, UK) and air dried at room temperature. Crosslink fixation was achieved by 3-min exposure of the membranes to UV light. Detection of CGMMV-Is and CFMMV was accomplished by hybridization with labeled RNA transcripts complementary to the cloned $\mathrm{CP}$ gene of each virus. Transcripts were prepared in vitro with T7 or SP6 RNA polymerase according to the manufacturer's instructions (Fermentas, Valnius, Lithuania).

Sequencing, sequence comparisons, and phylogenetic analysis. Sequencing of the CP of CGMMV-Is and the full genome of CFMMV was done by an automatic sequencer. The sequencing was carried out at the sequencing center of the Weizman Institute of Science, Rehovot, Israel.

Alignment analysis for percentage of identity calculation was carried out by means of the BCM search launcher multiple sequence alignment. The accession numbers of viruses retrieved from GenBank are AB015144 (KGMMV), AB015145 (CGMMVY), and D12505 (CGMMV-SH).

A phylogenetic analysis of the replicase and movement protein (MP) of the previously mentioned cucurbit-infecting Tobamoviruses was carried out by an on-line program, Drawgram of Biology Workbench, version 3.2. The program was operated with default settings including gaps and multiple substitutions from the alignment. Brome mosaic virus 2a protein (GenBank Accession No. X58457) and 3a protein (GenBank Accession No. X58458) served as out-group controls.

\section{RESULTS}

Host range and epidemiology. Infected greenhouse-grown cucumbers (Cucumis sativus cv. Hassan) were first identified in 1992 in the central part of Israel where cucumbers are grown as a monoculture in soil or on soilless media. Disease outbreaks normally occur during the summer and, to date, have not been observed outside this limited geographical area. Generally, under commercial greenhouse conditions, symptoms are first recognized on fruits and apical leaves at a relatively advanced growth stage. Symptoms on fruits are cultivar-dependent and include bright mottling or mosaic (Fig. 1A). Fruits exhibiting symptoms are unmarketable. Leaf symptoms include severe mosaic, veinbanding, and yellow mottling (Fig. 1B and C). In some cases, fully developed plants show severe wilting symptoms leading to plant collapse. Mechanical inoculation of seedlings under laboratory conditions led to symptom appearance as early as 2 weeks after inoculation. The symptoms induced by CFMMV in all tested cucurbits were always more severe than those induced by CGMMVIs (Fig. 1B and C).
The experimental host range of CFMMV was similar to that found for CGMMV-Is (Table 1). In contrast to CGMMV-Is, CFMMV induced chlorotic local lesions on D. stramonium, but like CGMMV-Is, it induced local lesions on Chenopodium amaranticolor (Table 1). CGMMV-Is and CFMMV also differed drastically in their effects on Cucurbita pepo cv. Maayan. Whereas CFMMV induced severe mosaic in this host, infection with CGMMV-Is resulted in faint yellow spots or a symptomless reaction (Fig. 1C, Table 1).

Virus purification, CP characterization, and serological relationships. An average virus yield of $0.6 \mathrm{mg} / \mathrm{g}$ of fresh tissue was normally obtained when the virus was purified from infected cucumber leaves. No contamination with host proteins was observed when virus preparations were analyzed on polyacrylamide gels (Fig. 2A, lane 2). Electron microscope analysis of viral preparations indicated the presence of rigid cylindrical particles with a modal length of $295 \mathrm{~nm}$, typical of those described for Tobamoviruses (data not shown).

The CP subunits of CFMMV showed a slightly lower mobility after SDS-PAGE than those of CGMMV-Is. However, their migration under these conditions was greater than that of the $\mathrm{CP}$ subunits of ToMV and PMMV (Fig. 2A).

In western blots analysis, antiserum against ToMV reacted strongly with its homologous $\mathrm{CP}$ and cross reacted strongly with the CPs of CFMMV and PMMV, but weakly with CGMMV-Is (Fig. 2B). Antisera against CV4 and CGMMV-Is reacted specifically with the CP band of CGMMV-Is (Fig. 2C and D), whereas the antisera against PMMV and CFMMV reacted only with their homologous virus, respectively (Fig. 2E and F).

DAS-ELISA analysis confirmed the lack of serological crossreaction between CGMMV-Is and CFMMV (data not shown). Commercial antisera against European isolates of CGMMV from both Loewe Phytodiagnostica and Agdia (data not shown) failed to react with CFMMV but reacted strongly with CGMMV-Is, indicating its specificity to CGMMV (Fig. 3).

Analysis of sequence homology by molecular hybridization. The riboprobe generated from the CP gene of CGMMV-Is reacted strongly with total RNA extracted from plants infected with CGMMV-Is and with its homologous virion RNA (Fig. 4A2 and A3). However, this probe did not react with total RNA extracted from plants infected with CFMMV or with virion RNA of this virus (Fig. 4A4 and A5). In reciprocal hybridization tests, a riboprobe produced from the CP gene of CFMMV reacted with total RNA isolated from CFMMV-infected plants and with its homologous virion RNA (Fig. 4B4 and B5), but failed to react with total RNA isolated from plants infected with CGMMV-Is and its virion RNA (Fig. 4B2 and B3).

TABLE 1. Experimental host range comparison for two Israeli cucurbitinfecting Tobamoviruses, Israeli isolate of Cucumber green mottle mosaic virus (CGMMV-Is) and Cucumber fruit mottle mosaic virus (CFMMV)

\begin{tabular}{lll}
\hline Host & CGMMV-Is & CFMMV \\
\hline Capsicum annuum & Nonhost & Nonhost \\
Chenopodium amaranticolor & Local lesions & Local lesions \\
Chenopodium quinoa & Symptomless & Symptomless \\
Citrullus vulgaris & Systemic mosaic & Systemic mosaic \\
Cucumis sativus cv. Beit alpha & Systemic mosaic & Systemic mosaic \\
Cucumis melo cv. Arava & Systemic mosaic & Systemic mosaic \\
Cucurbita pepo cv. Maayan & Symptomless or & Systemic mosaic \\
& yellow spots & \\
Gomphrena globosa & Nonhost & Nonhost \\
Datura stramonium & Nonhost & Chlorotic local lesions \\
Lycopersicon esculentum & Nonhost & Nonhost \\
\multicolumn{1}{c}{ cv. Marrmande } & & \\
Nicotiana glutinosa & Nonhost & Nonhost \\
Nicotiana tabacum cv. Samsun & Nonhost & Nonhost \\
Nicotiana benthamiana & Systemic mosaic & Leaf distortion, mosaic \\
Vigna sinensis cv. Black eye & Nonhost & Nonhost \\
\hline
\end{tabular}


Genome organization of CFMMV. The complete nucleotide sequence of CFMMV was determined (GenBank Accession No. AF321057). The genome consists of 6,562 nucleotides (nts). It has a $5^{\prime}$ and $3^{\prime}$ NCR of 62 and 228 nts, respectively. The coding part of the genome consists of four open reading frames (ORFs). The first two encode the short $(132 \mathrm{kDa})$ and long $(189 \mathrm{kDa})$ protein components of the putative viral replicase, 3,498 and 4,998 nts in length, respectively. The third is a $28-\mathrm{kDa}$ putative MP, $774 \mathrm{nts}$, and the fourth is the $17-\mathrm{kDa}$ CP consisting of $486 \mathrm{nts}$ (Fig. 5).
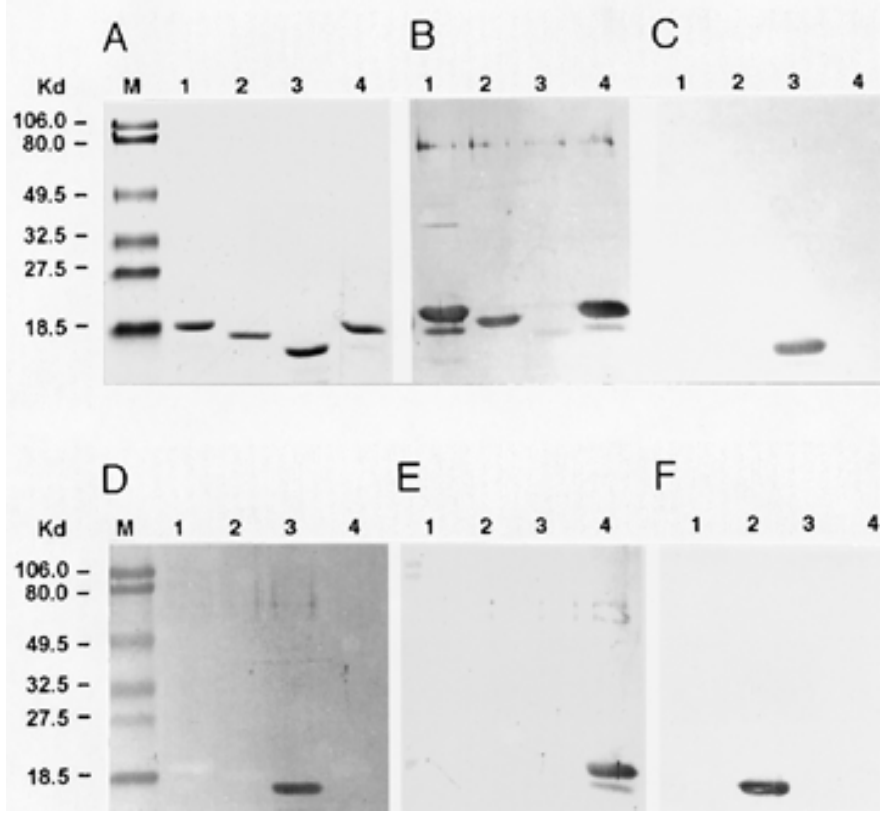

Fig. 2. Determination of serological relationships among different Tobamoviruses by western blots. Purified coat proteins of the following Tobamoviruses were separated on $10 \%$ sodium dodecyl sulfate-polyacrylamide gels and stained with Coomassie brilliant blue. A, Tomato mosaic virus (ToMV, lane 1), Cucumber fruit mottle mosaic virus (CFMMV, lane 2), Israeli variant of Cucumber green mottle mosaic virus (CGMMV-Is, lane 3), and Pepper mild mottle virus (PMMV, lane 4). Blots of identical gels were reacted with antisera against the following viruses: B, ToMV; C, CGMMV strain CV4; D, CGMMV-Is; E, PMMV; and F, CFMMV.

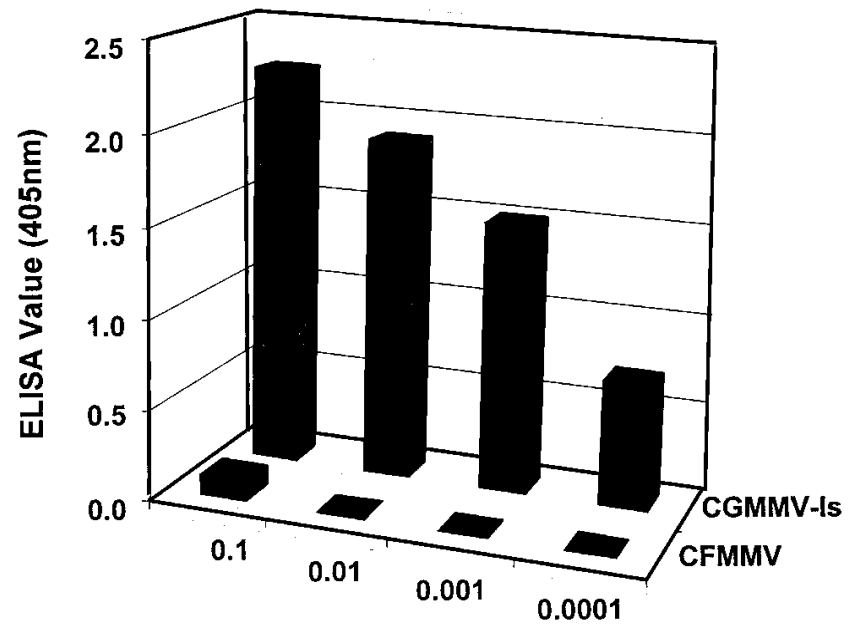

Virus Concentration ( $\mathrm{mg} / \mathrm{ml}$ )

Fig. 3. Double-antibody sandwich, enzyme-linked immunosorbent assay (ELISA) of purified preparations of the Israeli isolate of Cucumber green mottle mosaic virus (CGMMV-Is) and Cucumber fruit mottle mosaic virus (CFMMV) at various concentrations, with a commercial antiserum against a European isolate of CGMMV (Loewe Phytodiagnostica, Germany). ELISA values represent optical density readings after subtraction of background.
Sequence comparisons of the ORFs and NCRs among cucurbit-infecting Tobamoviruses. The length of the $5^{\prime}$ NCR of CFMMV is 62 nts (Fig. 5), compared with 57 and 60 bases found in the $5^{\prime} \mathrm{NCR}$ of CGMMV-Y and CGMMV-SH, respectively (data not shown). The $5^{\prime} \mathrm{NCR}$ sequences of the compared Tobamoviruses are highly variable, thus the identity of CFMMV with CGMMV-SH and CGMMV-Y were 50 and 56\%, respectively (Table 2). The nucleotide triplet that is immediately adjacent to the $\mathrm{m}^{7} \mathrm{Gppp}$ cap is GAU instead of GUA or GUU (6) as in other Tobamoviruses. The $\Omega$-like fragment of CFMMV, as in CGMMV-SH and CGMMV-Y, lacks the two eight base direct repeats (ACAAUUAC) starting at positions 12 and 59 of the ToMV 5' NCR (3). However, an equivalent incomplete motif (ACAUUACT) is located at position 35 of the putative $\Omega$ fragment of CFMMV, whereas the $5^{\prime} \mathrm{NCRs}$ of CGMMV-Y and CGMMV-SH are devoid of it (data not shown).

CFMMV has a $3^{\prime}$ NCR consisting of 228 nts, significantly longer than those of CGMMV-Y (164 nts) and CGMMV-SH (176 nts). This region has two blocks of identity among the compared Tobamoviruses: one between nucleotides 90 to 120 of the $3^{\prime}$ NCR and the second between nucleotides 188 to 228 (data not shown), however, in contrast to the others, CFMMV has a long variable sequence at the extreme $5^{\prime}$ end of the $3^{\prime}$ NCR (data not shown). The $3^{\prime}$ NCR of CFMMV has 49 and 56\% identity with the corresponding sequences of CGMMV-SH and CGMMV-Y, respectively (Table 2).

The number of the deduced amino acid residues of the putative replicase gene of CFMMV is 1,666, 4 amino acids (aa) shorter than, and $80 \%$ identical with the replicase of CGMMV-Y. However, it is longer by 18 aa and has only $62 \%$ identity with the corresponding amino acid sequence of CGMMV-SH (Table 2).

The putative MP of CFMMV comprises 258 aa residues, CGMMV-SH has 264 aa residues, and KGMMV and CGMMV-Y each contains 262 aa residues. The amino acid identity between the sequence of the putative MP of CFMMV and those of other cucurbit-infecting Tobamoviruses ranges from 61 to $75 \%$ (Table 2). The high amino acid identity (99\%; Table 2) between the MPs of KGMMV and CGMMV-Y indicated that these viruses are close strains of the same virus.

The CP sequence of CGMMV-Is is identical to that of CGMMV-SH (data not shown). The CPs of KGMMV and CGMMV-Y have the same number of amino acids (i.e., 169),

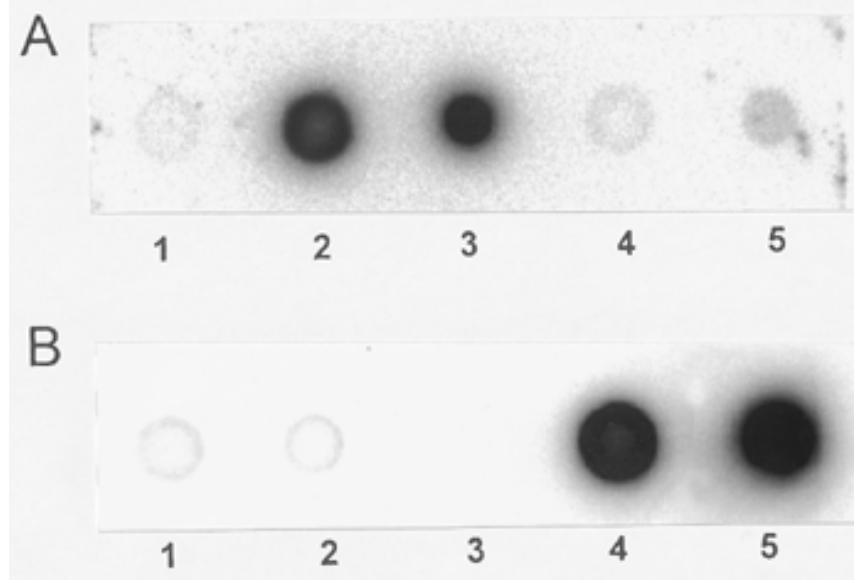

Fig. 4. Dot spot hybridization of RNA preparations of the Israeli isolate of Cucumber green mottle mosaic virus (CGMMV-Is) and Cucumber fruit mottle mosaic virus (CFMMV). RNA preparations were spotted onto nylon membranes as follows: A and B, lane 1,total RNA from uninfected cucumber leaves; lane 2, total RNA from leaves infected with CGMMV-Is; lane 3, CGMMV-Is virion RNA; lane 4, total RNA from leaves infected with CFMMV; and lane 5, CFMMV virion RNA. Membranes were hybridized with riboprobes prepared from the cloned coat protein gene of $\mathbf{A}$, CGMMVIs and $\mathbf{B}$, CFMMV. 
whereas CGMMV-SH and CFMMV have a CP subunit consisting of 162 and 161 aa, respectively (data not shown). A low sequence identity (45\%) was found between the CPs of CFMMV and CGMMV-SH, similar to the identity found between the CPs of CGMMV-SH and the other two Japanese isolates, KGMMV (44\%) and CGMMV-Y (42\%) (Table 2). However, CFMMV and KGMMV CPs share $77 \%$ identity, whereas a higher degree of sequence identity ( $88 \%$ ) was found between the corresponding sequences of KGMMV and CGMMV-Y (Table 2).

Phylogenetic analysis of the replicase and MP of cucurbitinfecting Tobamoviruses. The resulting phylogenetic tree for both analyses displayed two clusters of virus species. One cluster contained CGMMV-Y, KGMMV, and CFMMV, and the second cluster included CGMMV-SH and other sequenced isolates (e.g., CGMMV-W) with an identical sequence (Fig. 6).

\section{DISCUSSION}

Cucurbit-infecting Tobamoviruses can be distinguished biologically by the differing responses they elicit in Chenopodium amaranticolor and D. stramonium (4). CFMMV, like KGMMV and CGMMV-Y, induces local lesions in D. stramonium, in contrast to other CGMMV strains that fail to infect this host plant $(4,15)$. CFMMV also resembles KGMMV strains in its ability to infect Cucurbita pepo (Table 1) (28). However, unlike KGMMV, CFMMV induces local lesions in Chenopodium amaranticolor similarly to other strains of CGMMV. In nature, CFMMV is found only on cucumbers, where it causes severe fruit mottling and mosaic, but not fruit malformation as has been described for KGMMV and CGMMV-Y (4).

The genome organization of CFMMV, the size of its encoded proteins (Fig. 5), and its particle morphology fit the scheme described for the genus Tobamovirus (21). Our sequence results indi- cate that the size of the CP of CFMMV differs from those of CGMMV-SH and CGMMV-Is by a single additional amino acid. However, when it was analyzed by SDS-PAGE its mobility was disproportionally lower than that of the CP band of CGMMV-Is (Fig. 2). This anomaly was attributed to conformational changes caused by an increased content of $\alpha$ helix structure in CGMMV $\mathrm{CP}$ in the presence of SDS, which, in turn, increased its intrinsic negative charge density (25). These conformational differences may serve as a diagnostic means to differentiate among the various cucurbit-infecting Tobamoviruses by SDS-PAGE.
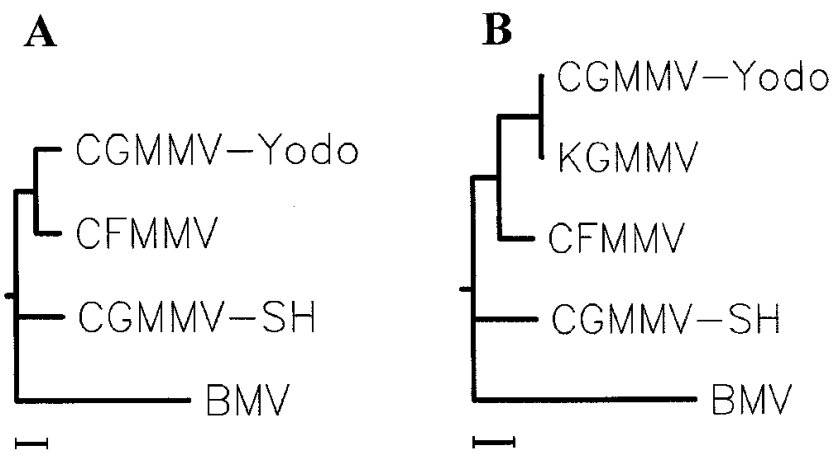

Fig. 6. Phylogenic analysis of $\mathbf{A}$, replicase and $\mathbf{B}$, movement protein (MP) of cucurbit-infecting Tobamoviruses: Cucumber fruit mottle mosaic virus (CFMMV), Yodo strain of Cucumber green mottle mosaic virus (CGMMVY), SH strain of CGMMV (CGMMV-SH), and Kyuri green mottle mosaic virus (KGMMV). The phylogenic trees were drawn with an on-line program (Drawgram Biology Workbench). Brome mosaic virus (BMV) 2a protein (GenBank Accession No. X58457) and 3a protein (GenBank Accession No. X58458) were applied as out-group controls for replicase and MP, respectively. Bars represent a genetic distance of 0.1 (10\% divergence). Branch values were $99 \%$ or greater.

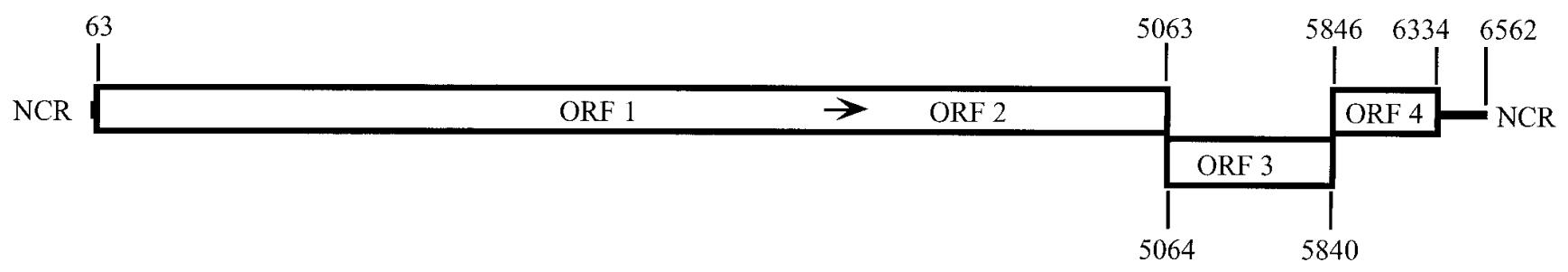

Fig. 5. Schematic representation of the genomic organization of Cucumber fruit mottle mosaic virus (CFMMV). The open reading frames (ORF) encoding four proteins: the putative shorter (ORF 1) and longer (ORF 2) components of the RNA replicase, the putative movement protein (ORF 3 ) and the coat protein (ORF 4). Noncoding regions (NCR) were found at the extreme $3^{\prime}$ and $5^{\prime}$ ends of the genome. Arrow stands for a read-through termination codon of ORF 1, and numbers denote the start or end nucleotide for each ORF. The full sequence of the genome is deposited as GenBank Accession No. AF321057.

TABLE 2. Percent identities for pairwise nucleotide sequence comparisons of the $5^{\prime}$ and $3^{\prime}$ noncoding regions (NCRs) and amino acid sequence comparisons of replicase (Rep; 189-kDa component), movement protein (MP), and coat protein (CP) among cucurbit-infecting Tobamoviruses, Cucumber fruit mottle mosaic virus (CFMMV), Cucumber green mottle mosaic virus SH strain (CGMMV-SH) and Yodo strain (CGMMV-Y) and Kyuri green mottle mosaic virus (KGMMV) ${ }^{\mathrm{a}}$

\begin{tabular}{|c|c|c|c|c|c|c|c|c|c|c|c|c|c|}
\hline & \multirow[b]{2}{*}{ Virus } & \multicolumn{2}{|c|}{$5^{\prime} \mathrm{NCR}$} & \multicolumn{2}{|r|}{ Rep } & \multicolumn{3}{|c|}{ MP } & \multicolumn{3}{|c|}{$\mathrm{CP}$} & \multicolumn{2}{|c|}{$3^{\prime} \mathrm{NCR}$} \\
\hline & & CFMMV & CGMMV-SH & CFMMV & CGMMV-SH & CFMMV & CGMMV-SH & Yodo & CFMMV & CGMMV-SH & Yodo & CFMMV & CGMMV-SH \\
\hline \multirow{2}{*}{$5^{\prime} \mathrm{NCR}$} & CGMMV-SH & 50 & & $\ldots$ & $\ldots$ & $\ldots$ & $\ldots$ & $\ldots$ & $\ldots$ & $\ldots$ & $\ldots$ & $\ldots$ & $\ldots$ \\
\hline & CGMMV-Y & 56 & 61 & $\ldots$ & $\ldots$ & $\ldots$ & $\ldots$ & $\ldots$ & $\ldots$ & $\ldots$ & $\ldots$ & $\ldots$ & $\ldots$ \\
\hline & CGMMV-Y & $\ldots$ & $\ldots$ & 80 & 63 & $\ldots$ & $\ldots$ & $\ldots$ & $\ldots$ & $\ldots$ & $\ldots$ & $\ldots$ & $\ldots$ \\
\hline \multirow[t]{2}{*}{ MP } & CGMMV-SH & $\ldots$ & $\ldots$ & $\ldots$ & $\ldots$ & 61 & $\ldots$ & $\ldots$ & $\ldots$ & $\ldots$ & $\ldots$ & $\ldots$ & $\ldots$ \\
\hline & CGMMV-Y & $\ldots$ & $\ldots$ & $\ldots$ & $\ldots$ & 75 & 58 & $\ldots$ & $\ldots$ & $\ldots$ & $\ldots$ & $\ldots$ & $\ldots$ \\
\hline & CGMMV-Y & $\ldots$ & $\ldots$ & $\ldots$ & $\ldots$ & $\ldots$ & $\ldots$ & $\ldots$ & 77 & 42 & $\ldots$ & $\ldots$ & $\ldots$ \\
\hline & KGMMV & $\ldots$ & $\ldots$ & $\ldots$ & $\ldots$ & $\ldots$ & $\ldots$ & $\ldots$ & 77 & 44 & 88 & $\ldots$ & $\ldots$ \\
\hline \multirow[t]{2}{*}{$3^{\prime} \mathrm{NCR}$} & CGMMV-SH & $\ldots$ & $\ldots$ & $\ldots$ & $\ldots$ & $\ldots$ & $\ldots$ & $\ldots$ & $\ldots$ & $\ldots$ & $\ldots$ & 49 & $\ldots$ \\
\hline & CGMMV-Y & $\ldots$ & $\ldots$ & $\ldots$ & $\ldots$ & $\ldots$ & $\ldots$ & $\ldots$ & $\ldots$ & $\ldots$ & $\ldots$ & 56 & 55 \\
\hline
\end{tabular}

a GenBank accession numbers of sequence data used for the calculation of percent identity: CFMMV (AF321057), CGMMV-SH (D12505), CGMMV-Y (AB015145), and KGMMV (CGMMV-C) (AB015144). 
Our studies indicate clearly that CFMMV is serologically distinct from CGMMV-Is, CV4, and PMMV. CGMMV-Is is a biological variant of CGMMV (2), and our western blot data confirmed its close serological relationship to CV4, which has been claimed to be serologically similar to CGMMV-W and CGMMVSH $(9,22,28)$. Interestingly, CFMMV cross reacted significantly with ToMV antiserum, a result similar to previous studies showing a higher cross reaction between CGMMV-W and the common strain of ToMV than that obtained between CGMMV-W and CGMMV-C (22). Thus, in both cases serological relatedness does not reflect relatedness with respect to the biological properties of the compared viruses. Furthermore, cross reactivity is not always correlated with sequence similarity (32).

The remoteness of the relationship between CFMMV and CGMMV-Is (identical to CGMMV-SH) is further supported by the relatively low amino acid sequence homology (45\%) between their CPs (Table 2), and by the results of the hybridization experiments that showed no cross hybridization between the $\mathrm{CP}$ genes of the two viruses (Fig. 4).

It has been indicated that the taxonomy of cucurbit-infecting Tobamoviruses is unsatisfactory (9). It is difficult to define exactly the criteria that should be used in deciding whether two related viruses are distinct viruses or strains of the same virus. The taxonomic status of a virus was determined in the past by serological and host-range criteria (13), but the availability of sequence data has provided a more reliable tool to be used for virus classification. According to the International Committee on the Taxonomy of Viruses, species demarcation in the genus Tobamovirus are based on the following criteria: sequence similarity, host range, and antigenic relationships among the CPs (21). Gibbs (12) has used CP sequence alignment of definitive Tobamoviruses to determine the evolutionary distances within this group of viruses and reported CP amino acid sequence identity of distinct Tobamoviruses ranging between 37 and 82\% (12). According to Gibbs (12), the relationships among MPs (30 K proteins) of Tobamoviruses resemble those exhibited by the CPs of the same viruses. We have demonstrated a similar trend (Table 2). A close approach was proposed later for classification of Potyviruses (10). Pairwise strain sequence comparisons in the genus Potyvirus show a high level of identity (94 to 99\%), irrespective of the gene product being considered, whereas the range of identities found among distinct virus nucleic acids ranged from 30 to $60 \%$ (10). It has been proposed that $\mathrm{CP}$ sequence data could be used to develop a rationally designed system for Potyvirus identification and classification (27). The use of the amino acids composition of virus proteins for classification was supported by Fauquet et al. (8), who found that most virus MPs fell into groups that correlated closely with the accepted groups of plant viruses.

In accordance with the previously mentioned schemes, in the light of the distinct differences between the antigenic properties (Figs. 2 and 3) and the low homology between the amino acid sequences of both CPs and MPs (45 and 61\%, respectively) (Table 2 ), we propose that CFMMV and CGMMV-Is (identical to CGMMV-SH in sequence) are distinct viruses. Amino acid sequence homology of the CPs and MPs (77 and 75\%, respectively) of CFMMV and KGMMV indicate a much closer relationship. However, based on the rationale of the classification scheme offered by Gibbs (12), the distance between these viruses may still be sufficiently great to justify their classification as distinct viruses.

The sequence data, phylogenetic analysis, and biological information presented in this study support the separation of the cucurbit-infecting Tobamoviruses into two subgroups: subgroup I comprised of the strains and isolates referred to as CV3, CV4, CGMMV-W, CGMMV-SH, and CGMMV-Is, and subgroup II comprised of KGMMV, CGMMV-Y, and CFMMV. The first two members of subgroup II are closely related both biologically and in their sequence (Table 2) and may be considered as strains of the same virus.

\section{LITERATURE CITED}

1. Ainworth, G. C. 1935. Mosaic disease of cucumber. Ann. Appl. Biol. 22:55-67.

2. Antignus, Y., Pearlsman, M., Ben Joseph, R., and Cohen, S. 1990. Occurrence of variant of cucumber green mottle mosaic virus in Israel. Phytoparasitica 18:50-56.

3. Avila-Rincon, M. J., Ferrera, M. L., Alonso, E., Garcia-Luque, I., and Diaz-Ruiz, J. R. 1989. Nucleotide sequence of $5^{\prime}$ and $3^{\prime}$ non-coding regions of pepper mild mottle virus strains. J. Gen. Virol. 70:3025-3031.

4. Brunt, A. A., Crabtree, K., Dallwitz, M. J., Gibbs, A. J., Watson, L., and Zurcher, E. J., eds. 1996. Plant Viruses Online: Descriptions and Lists from the VIDE Database. Published by the Australian National University, Canberra, Australia.

5. Clark, M. F., and Adams, A. N. 1977. Characterization of the microplate method of enzyme linked immunosorbent assay for detection of plant viruses. J. Gen. Virol. 34:475-483.

6. Davies, J. W., and Hull, R. 1982. Genome expression of plant positivestrand RNA viruses. J. Gen. Virol. 61:1-14.

7. Dodds, J. A. 1993. dsRNA in diagnosis. Pages 273-294 in: Diagnosis of Plant Virus Diseases. R. E. F. Matthew, ed. CRC Press, Boca Raton, FL.

8. Fauquet, C., Dejardin, J., and Thouvenel, J. C. 1986. Evidence that the amino acid composition of the particle proteins of plant viruses is characteristic of the virus group. I. Multidimensional classification of plant viruses. Intervirology 25:1-13.

9. Francki, R. I. B., Hu, J., and Palukaitis, P. 1986. Taxonomy of cucurbitinfecting Tobamovirus as determined by serological and molecular hybridization analyses. Intervirology 26:156-163.

10. Frenkel, M. J., Jilka, J. M., Shukla, D. D., and Ward, C. W. 1992. Differentiation of Potyviruses and their strains by hybridization with the $3^{\prime}$ non-coding region of the viral genome. J. Virol. Methods 36:51-62.

11. Frohman, M. A. 1990. RACE: Rapid amplification of cDNA ends. Pages 28-38 in: PCR Protocols: A Guide to Methods and Applications. M. A. Innis, D. H. Gelfand, J. J. Sninsky, and T. J. White, eds. Academic Press, San Diego.

12. Gibbs, A. J. 1986. Tobamovirus classification. Pages 167-180 in: The Plant Viruses. Vol. 2. The Rod Shaped Plant Viruses. M. H. V. van Regenmortel and H. Fraenkel-conrat, eds. Plenum Press, New York.

13. Hamilton, R. I., Edwardson, J. R., Francki, R. I. B., Hsu, H. T., Hull, R. Koenig, R., and Milne, R. G. 1981. Guidelines for the identification and characterization of plant viruses. J. Gen. Virol. 54:223-241.

14. Hibi, T., and Saito, Y. 1985. A dot immunobinding assay for the detection of tobacco mosaic virus in infected tissues. J. Gen. Virol. 66:1191-1194.

15. Hollings, M., Komuru, Y., and Tochiara, H. 1975. Cucumber green mottle mosaic virus. No. 154 in: Descriptions of Plant Viruses. Commonw. Mycol. Inst./Assoc. Appl. Biol., Kew, England.

16. Huet, H., Gal-On, A., Meir, E., Lecoq, H., and Raccah, B. 1994. Mutations in the helper component protease gene of zucchini yellow mosaic virus affect its ability to mediate aphid transmissibility. J. Gen. Virol. 75:1407-1414

17. Inoue, T., Inoue, N., Asatani, M., and Mitsuhata, K. 1967. Studies on cucumber green mottle mosaic virus in Japan (in Japanese). Nogaku Kenkyu 51:175-186.

18. Kitani, K., Kiso, A., and Shigematsu, Y. 1970. Studies on a new virus disease of cucumber Cucumis sativus L. var. F1 Kurume-Otiai-H type discovered in Yodo (in Japanese). Proc. Assoc. Plant Prot. Shikoku 5:59-66.

19. Komuru, Y., Tochihara, H., Fukatsu, R., Nagai, Y., and Yoneyama, S. 1968. Cucumber green mottle mosaic virus on watermelon in Chiba and Ibaraki Prefectures (in Japanese). Ann. Phytopathol. Soc. Jpn. 34:377.

20. Laemmli, U. K. 1970. Cleavage of structural proteins during assembly of head bacteriophage T4. Nature (Lond.) 227:680-685.

21. Lewandowski, D. 2000. Genus Tobamovirus. Pages 889-894 in: Virus Taxonomy. Seventh Report of the International Committee of Taxonomy of Viruses. M. H. V. van Regenmortel, C. M. Fauquet, D. H. L. Bishop, E. B. Carstens, M. K. Estes, S. M. Lemon, J. Maniloff, M. A. Mayo, D. J. McGeoch, C. R. Pringle, and R. B. Wickner, eds. Academic Press, San Diego.

22. Nozu, Y., Tochihara, H., Komuro, Y., and Okada, Y. 1971. Chemical and immunological characterization of cucumber green mottle mosaic virus (watermelon strain) protein. Virology 45:577-585.

23. Palukaitis, P., and Symons, R. H. 1980. Nucleotide sequence homology of thirteen tobamovirus RNAs as determined by hybridization analysis with complementary DNA. Virology 107:354-361.

24. Rosner, A., Bar-Joseph, M., Moskovitz, M., and Mevarech, M. 1983. Diagnosis of specific viral RNA sequences in plant extracts by hybridization with a polynucleotide kinase-mediated, ${ }^{32} \mathrm{P}$-labeled, doublestranded RNA probe. Phytopathology 73:699-702.

25. Saito, T., Imai, Y., Meshi, T., and Okada, Y. 1988. Interviral homologies of the 30K proteins of tobamoviruses. Virology 167:653-656.

26. Sano, Y., Nozu, Y., and Inoue, H. 1978. Anomalous mobility of cucum- 
ber green mottle mosaic virus protein in sodium dodecyl sulfatepolyacrylamide gel electrophoresis. J. Biochem. 84:1041-1049.

27. Shukla, D. D., and Ward, C. W. 1988. Amino acid sequence homology of coat proteins as a basis for identification and classification of the Potyvirus group. J. Gen. Virol. 69:2703-2710.

28. Tan, S. H., Nishiguchi, M., Murata, M., and Motoyoshi, F. 2000. The genome structure of kyuri green mottle mosaic tobamovirus and its comparison with that of cucumber green mottle mosaic tobamovirus. Arch. Virol. 145:1067-1079.

29. Tung, J. S., and Knight, C. A. 1972. The coat protein subunits of cucumber viruses 3 and 4 and a comparison of methods for determining their weights. Virology 48:574-581.

30. Ugaki, U., Tomiyama, M., Kakutani, T., Hidaka, S., Kiguchi, T., Nagata,
R., Sato, T., Motoyoshi, F., and Nishiguchi, M. 1991. The complete nucleotide sequence of cucumber green mottle mosaic virus (SH strain) genomic RNA. J. Gen. Virol. 72:1487-1495.

31. Van De Walle, M. J., and Siegel, A. 1982. Relationships between strains of tobacco mosaic virus and other selected plant viruses. Phytopathology 72:390-395

32. van Regenmortel, M. H. V. 1975. Antigenic relationships between strains of tobacco mosaic virus. Virology 64:415-420.

33. Vasudeva, R. S., Raychaudhuri, S. P., and Singh, J. 1949. A new strain of Cucumis virus 2. Indian Phytopathol. 2:180-185.

34. Wetter, C., Conti, M., Altschuh, R., Tabillion, R., and van Regenmortel, M. H. V. 1984. Pepper mild mottle virus, a tobamovirus infecting pepper cultivars in Sicily. Phytopathology 74:405-410. 